\title{
Harry Ernest Wheeler, 1919 to 1999
}

\author{
Thomas Pirone, Lisa Vaillancourt, and H. H. Luke
}

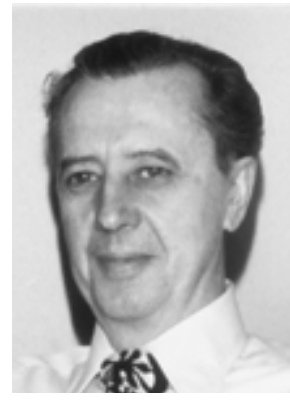

Harry Wheeler, emeritus professor of plant pathology at the University of Kentucky, died on 12 July 1999 after several months of illness. Harry was born 25 January 1919 in West Charleston, VT. He received a Senatorial Scholarship to the University of Vermont and there received a B.S. degree in 1941. Harry was in the first class of Army Air Corps cadets to learn celestial navigation and was assigned to the Ferry Command, which required the best navigators. After 4 years of service, he was honorably discharged with the rank of captain. In 1946, Harry started his graduate training at Louisiana State University (LSU), Baton Rouge, and received a M.S. degree in 1947 and a Ph.D. degree in 1949, both in botany. In 1949-1950, Dr. Wheeler was a visiting investigator and research participant at the Oak Ridge National Laboratory, Oak Ridge, TN. He returned to LSU in 1950 as an assistant professor and advanced to the rank of professor in 1959. In 1958, Dr. Wheeler was on leave as a John Simon Guggenheim Fellow and research fellow in biology at Harvard University, Cambridge, MA. Harry stayed at LSU until 1967, when he accepted a position as professor of plant pathology at the University of Kentucky, Lexington, where he remained until his retirement in 1984.

Dr. Wheeler was the author or coauthor of over 100 papers in the areas of fungal genetics and physiology of parasitism, including articles in the Annual Review of Microbiology and the Annual Review of Phytopathology. He was best known for his research on sexuality in Glomerella and on the causal role of the pathotoxin victorin. Dr. Wheeler was also one of the first to use radioisotopes to study host-parasite physiology and microbial toxins in plant disease.

Dr. Wheeler was a pioneer in the field of fungal sexuality. His cytological and physiological studies of Glomerella involved concurrent research on sexual strains, sexual hormones, and the genetic factors involved in perithecium and ascus development. His landmark cytological study of sexual development in Glomerella is still valued as one of very few such studies in ascomycetes. His genetic work was always of the highest standard, and he and his colleagues were among the first to make routine use of tetrads in their analyses. In 1954, Dr. Wheeler summarized his numerous works of research and proposed that cross fertility in Glomerella is regulated by several unlinked, multiallelic loci through a process called unbalanced heterothallism. Dr. Wheeler's work was highly respected by his peers as evidenced by its prominent treatment in many contemporary reviews of fungal sexuality.

In 1952, Dr. Wheeler began to investigate the role of toxins in plant disease. Because conclusive evidence that plant pathogens produce toxins that incite disease development was lacking, Dr. Wheeler used victorin to test the toxin theory and as a tool to investigate the nature and course of disease development. He reasoned that microbial toxins, substituted for microbes, would permit a quantitative approach to the study of the nature of disease. He developed techniques to produce large quantities of victorin and devised a sensitive bioassay for the toxin. Using these tools, he and his students subsequently obtained conclusive evidence to validate the toxin theory of plant disease and developed new techniques to probe the basic nature of plant pathogenesis. Using victorin as a screening agent, a

Publication no. P-1999-1004-040 method was developed to study mutation rates in higher plants. This study was the first to show that mutation rates in higher plants were similar to those of microorganisms. This work received wide recognition and was the subject of an article in Time on 2 January 1956.

Dr. Wheeler's pioneering work on the physiology of disease revealed that toxins caused susceptible tissue to leak electrolytes. He concluded that increased respiration caused by toxin treatment was a product of, and not the cause of, disease. This observation led to two new concepts in plant pathology. Dr. Wheeler proposed that invading pathogens trigger an initial malfunction of the host (initial trigger concept) and that the initial malfunction sets in motion a series of reactions that lead to the other physiological and visual symptoms (the physiological syndrome concept). He developed the "pathotoxin hypothesis" and four rules of proof. Dr. Wheeler's success in the development of a satisfactory hypothesis was due to his ability to conceptualize the total problem and reduce it to its simplest form. Some of his other studies contributed greatly to our understanding of host-parasite interactions at the biochemical and ultrastructural levels. His 1975 book, Plant Pathogenesis, critically evaluated current knowledge on the topic and introduced the concept of the physiological syndrome as an ordered sequence of changes characteristic of many plant diseases.

In addition to the Guggenheim Fellowship, Harry's honors and positions in scientific societies included Fellow of the American Association for the Advancement of Science and of The American Phytopathological Society (APS); Southern Division of APS Outstanding Plant Pathologist Award; University of Kentucky Research Foundation Distinguished Research Award; APS delegate to the 10th International Botanical Congress; membership on the editorial boards of Phytopathology and Mycologia; chairman of the Research Grants Committee of the Mycological Society of America; member of the Executive Committee of the Association of Southeastern Biologists; president of the Louisiana Academy of Sciences; chairman of the Activities Committee of the Southeastern Section of the Botanical Society of America; member of National Science Foundation Predoctoral Fellowship Panels; and president of the LSU chapter of Sigma Xi. He was listed in American Men of Science and Gallery of Contemporary Noted Mycologists.

Harry was scrupulously honest and, typical of his Vermont heritage, had the courage to stand up for his principles. He was a toughminded individual with very high standards. Many a graduate student, postdoc, and fellow faculty member experienced his scornful appraisal of an experiment or a draft of a manuscript. Some may have regarded this as mean-spirited, but those who knew him well realized that it was sincere, and those who heeded his appraisals became better scientists as a result. Through much of his career, Harry had few serious interests outside of science, but a few years after his arrival in Kentucky he developed an enthusiasm for thoroughbred horse racing. Following his retirement, racing occupied much of his time and his skills, honed by his sharp intellect, were highly regarded by his fellow handicappers at Keeneland racecourse.

Harry was preceded in death by his beloved wife, Naomi, an accomplished artist with whom Harry collaborated in developing "electron printing" as an art form. A sister, Marion Wheeler Woodcock, and a brother, Gary Hollis Wheeler, Jr., also predeceased him. Survivors include a brother, Harold W. Wheeler, of Newville, PA; a sister, Phoebe M. DuVall, of Deltona, FL; a sister-in-law, Dorothy Lord Wheeler, of West Charleston, VT; and several nieces and nephews. 